\title{
Electrophoretic Deposition of Carbon Nanotubes Electrode for Dye-Sensitized Solar Cells
}

\author{
Shun Fukutomi, Kazuaki Tamiya, Takaharu Watanabe, Kozo Taguchi \\ Ritsumeikan University \\ Japan
}

\begin{abstract}
Generally dye-sensitized solar cell (DSSC) consists of a transparent electrode, TiO2, dye, electrolysis solution and Pt as a counter electrode. In our study, we substituted carbon nanotubes (CNT) for counter electrodes to improve the performance of DSSC owing to their advantages as high catalytic activity, large surface area, and low cost. To coat CNT with Fluorine doped tin oxide(FTO) glass, we adopted Electrophoretic deposition (EPD). It was shown to be a convenient method to fabricate uniform coatings of CNT with desired thickness changing voltage, electrophoresis time and inter electrode distance [1]. After EPD, we intered FTO glass coated CNT and we changed sintering temperature of it. As a result of having observed it with atomic force microscopy (AFM), surface area of CNT improved if baking temperature rose. From this result, improvement in the conversion efficiency of DSSC is expectable and sintering temperature after EPD is very important for DSSC.
\end{abstract}

Keywords-dye-sensitized solar cells; carbon nanotubes; electrophoretic deposition; surface area

\section{INTRODUCTION}

Electricity is indispensable when we live. Although it makes our life very comfortable, there are many problems in the case of power generation. For example Global Warming. One of the causes of Global Warming is emission of carbon dioxide. Thermal power generation is one of the high efficient power generation methods but it is also the power generation method which emits the carbon dioxide which caused Global Warming.

A solar cell generates electric energy using sunlight. It does not generate a carbon dioxide like the thermal power generation which burns oil and generates electricity at the time of power generation. Therefore a solar cell is the best power generation method for environment. However a solar cell which made of silicon is expensive to product. On the other hand, the production cost of a dye-sensitized solar cell (DSSC) is cheap, and it is a low price of about $1 / 10$ of a silicon type solar cell. So DSSC has been studied by many scientists.

Recently carbon nanotubes (CNT) attract attention. CNT has high catalytic activity, large surface area, so CNT is used as a counter electrode of DSSC replaced with Pt.

In this study, we show for the surface area rate of the CNT electrode with different sintering time after the EDP.

\section{DSSC}

Generally dye-sensitized solar cell(DSSC) consist of a transparent electrode, $\mathrm{TiO}_{2}$,dye, electrolysis solution and $\mathrm{Pt}$ or CNT as counter electrode as shown in figure. 1. Compare with a silicon type solar cell, DSSC is cheap and structure is simple and large equipment is no need for production. These are DSSC`s features.

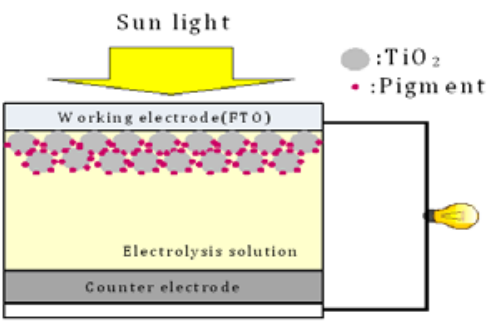

FIGURE I. STRUCTURE OF DSSC.

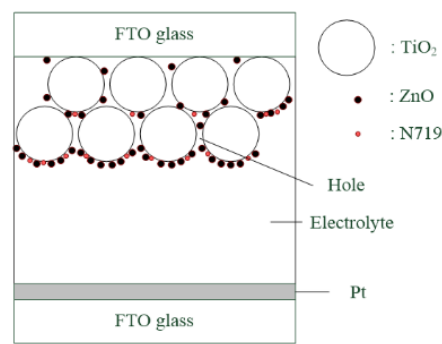

FIGURE II. STRUCTURE OF DSSC WITH ZNO COATING.

The theory of a DSSC is shown below. When solar light energy hits pigment, the electron in pigment will be excited. The excited electron is sent to working electrode through TiO2. It is sent to a counter electrode through external load. In a counter electrode, I3- in an electrolysis solution receives an electron and turns into 3I-. I-pass an electron to the dye molecule which moved and lost the electron, and return to the original state. This is theory, DSSC can change light energy to electrical energy.

We had already attained in 3.8\% of conversion efficiency using ZnOcoated on $\mathrm{TiO} 2$ as a working electrode of DSSC and we used N-719 as a pigment and Pt as a counter electrode of this DSSC. Fig. 2 shows structure of DSSC with $\mathrm{ZnO}$ coating. Previous studies have shown that the layer of $\mathrm{ZnO}$ of DSSC is important for the increase of power conversion efficiency. Generally, rf magnetron sputtering is used to coat $\mathrm{ZnO}$ with $\mathrm{TiO} 2$ electrode and DSSC used its $\mathrm{TiO} 2$ electrode coated $\mathrm{ZnO}$ as working electrode has increased power conversion efficiency from $4.76 \%$ to $6.55 \%$ [2]. There is also simple dip coating method to coat $\mathrm{ZnO}$ with $\mathrm{TiO}$. DSSC 
with working electrode manufactured simple dip coating has increased efficiency from $3.17 \%$ to $3.85 \%$ [3]. Obviously, the power conversion efficiency of the DSSC with TiO2 electrode coated ZnOby rf magnetron sputtering is higher than the DSSC with TiO2 electrode coated ZnOby simple dip coating.However, the rf magnetron sputtering method needsexpensive vacuum technology, so we manufacture $\mathrm{TiO} 2$ electrode coated $\mathrm{ZnO}$ using simple dip coating method. Then we controlled band gap of a $\mathrm{TiO} 2$ electrode coated $\mathrm{ZnO}$ to create energy barrier because the layer of $\mathrm{ZnO}$ can increase of power conversion efficiency for prevent the escape of the move back electron from $\mathrm{TiO} 2$ to electrolyte. We show how to manufacture working electrode below.The first step of making the layer of $\mathrm{TiO} 2$ is following. First, the colloid of $\mathrm{TiO} 2$ was mixedTiO2, ethanol, acetylacetone and Triton X-100. The colloid of $\mathrm{TiO} 2$ was distributed by means of magnetic stirrer for 24 hours. Then the colloid of TiO2is put on 24 hours for precipitate of clotted of $\mathrm{TiO} 2$. After we put the electrode inside an ultrasound bath for 30 minutes, the electrode was immersing in the TiCl4 solution for 30 minutes, and then the solution on electrode was put in ethanol and then pure water for cleaning. Finally, the colloid of $\mathrm{TiO} 2$ was spin coated on the electrode 5 times by spinner. After that, the $\mathrm{TiO} 2$ coating with electrode was sintered at $450^{\circ} \mathrm{C}$ for 1 hour by electric furnace. Also, the electrode needed TiCl4 treatment, and then the electrode was sintered at $450^{\circ} \mathrm{C}$ for 1 hour by electric furnace.

The second step of making the layer of $\mathrm{ZnO}$ on $\mathrm{TiO} 2$ is following. First, the solution of thezinc acetate dehydrate with ethanol were mixing by means of magnetic stirrer. After the TiO2coating withelectrode was immersed by the solution of thezinc acetate dehydrate and ethanol at $25^{\circ} \mathrm{C}$, the layer of $\mathrm{ZnO}$ on $\mathrm{TiO} 2$ was sintered at $450^{\circ} \mathrm{C}$ for 30 minutes by electric furnace.

The third step of making the DSSC is following. First, the ZnO-coated TiO2 electrode was immersed by the N-719 with ethanol of $70^{\circ} \mathrm{C}$ for $6 \mathrm{~h}$. And then this electrode was put in ethanol for a little time. After that, the liquid electrolyte was injected into between the electrode and the opposite electrode with the layer of Pt.

\section{EPD}

To coat CNT with FTO glass, we used EPD. The theory of EPD is shown below and fig. 3 shows overview of EPD. Powder particles are charged positively or negatively by variety causes in the liquid. These powder particles move toward the electrode by applying an electric field. Then these powder particles deposit on the surface of the electrode and become thick film form. In the case of CNT, CNT is negatively charged in the liquid so CNT moves to the anode. Fig.4 and Table1 show thickness of CNT film applied a constant DC voltage of $15 \mathrm{~V}$ for different times. From this result, it turns out that the thickness of CNT film can be controlled by using EPD.

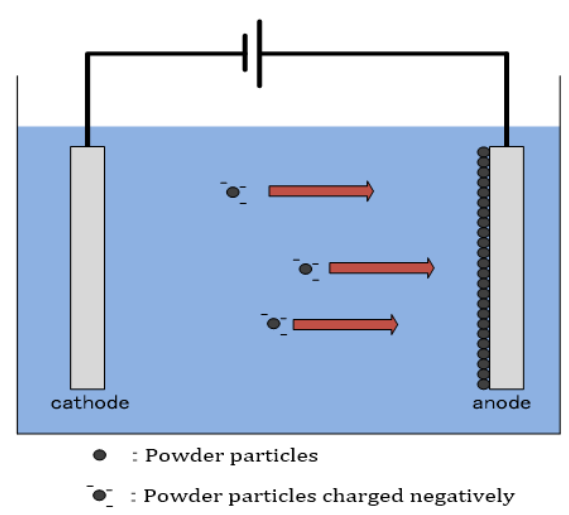

FIGURE III. OVERVIEW OF EPD.

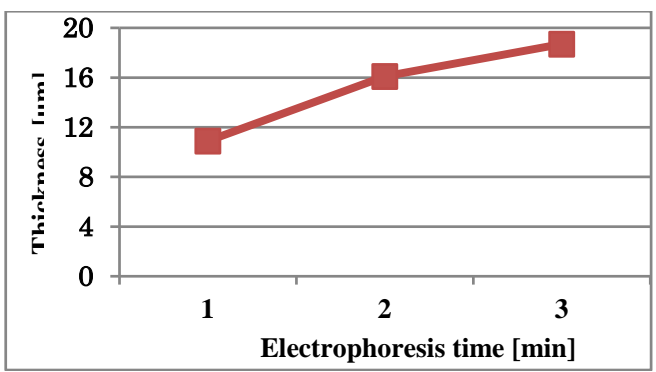

FIGURE IV. THICKNESS OF CNT FILM.

\section{EXPERIMENT}

We used CNT instead of Pt as a counter electrode of DSSC. CNT has the feature of large surface area, high catalytic activity, and low cost. At present several methods have been employed for the fabrication of CNT counter electrodes such as chemical vapor deposition, screen-printing, drop-coating, spin-coating, and spray coating [4][5].We use EDP to coat CNT with FTO glass because thickness of CNT is important for high efficiency DSSC.

We used CNT dispersion (Meijo Nano Carabon Co., Ltd., Japan). This CNT dispersion is dispersed multi walled CNT and isopropyl alcohol as the solvent, and its concentration is 1\%. Fig. 5 shows experiment system of EDP. Aluminum was used as a substrate, connected to the negative potential, and the counter electrode is FTO with same area. Two electrodes were kept parallel at $9 \mathrm{~mm}$ apart in the suspension. There is a report that a thickness of about $12 \mu \mathrm{m}$ is the best in the CNT counter electrode of DSSC [6]. In order to control the thickness of the CNT film about $12 \mu \mathrm{m}$, the EPD was carried out by applying a constant DC voltage of $15 \mathrm{~V}$ for a minute and the film thickness of CNT was able to attain the thickness of $10.9 \mu \mathrm{m}$. 


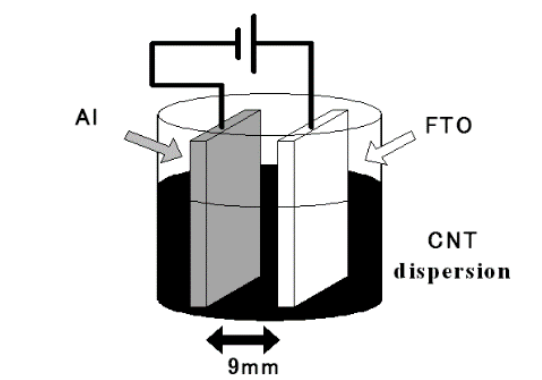

FIGURE V. EXPERIMENT SYSTEM OF EPD.

After EPD, we sintered counter electrode coated CNT. Then we changed sintering temperature of it because as a result of having observed it with atomic force microscopy (AFM), surface area of CNT change if sintering temperature change. If the contact surface area of an electrolysis solution and CNT electrode is large, the high efficiency of a DSSC can be expected with the catalytic ability of CNT.

\section{RESULT}

We measured the surface area rate of the CNT by AFM and measurement area is $5 \mu \mathrm{m} \times 5 \mu \mathrm{m}$. The surface area rate is defined as the rate of the surface shape of the CNT and the area of the flat area. Fig. 6-9 shows the surface shape of the CNT electrode was measured by AFM. These CNT electrode were sintered different temperature $\left(300^{\circ} \mathrm{C}, 400^{\circ} \mathrm{C}, 500^{\circ} \mathrm{C}\right.$, $550^{\circ} \mathrm{C}$ ). It is found that $\mathrm{CNT}$ has shape like bamboo from these figures. This structure such as bamboo has increased surface area of the CNT. Fig. 10 show surface area rate of CNT electrode sintered at different temperature. From this result, the surface area of CNT improves if sintering temperature is raised. However surface area of CNT electrode sintered at $500^{\circ} \mathrm{C}$ is larger than $550^{\circ} \mathrm{C}$, and it turns out that surface area decreases if a fixed temperature is exceeded. surface area rate of CNT sintered at $500^{\circ} \mathrm{C}$ is 2.78 . It has the highest surface area of all sintered CNT electrodes. We could not prepare the CNT electrode sintered at over $600^{\circ} \mathrm{C}$ because CNT deposited on FTO was burned. Therefore sintering at $500^{\circ} \mathrm{C}$ is the best for CNT counter electrode of DSSC and it is possible to expect a good conversion efficiency.

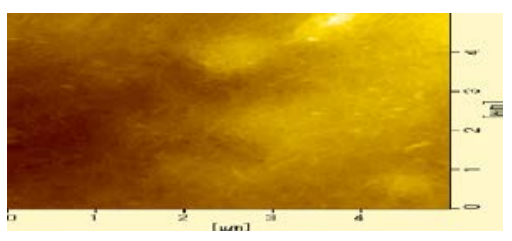

FIGURE VI. SURFACE SHAPE OF CNT(AT 300

$\left.{ }^{\circ} \mathrm{C}\right)$.

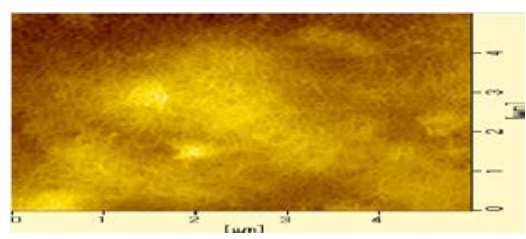

FIGURE VII. At $400^{\circ} \mathrm{C}$.

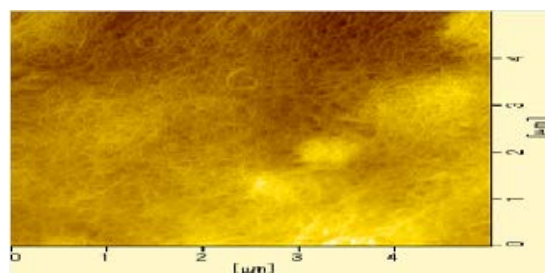

FIGURE VIII. At $500^{\circ} \mathrm{C}$.

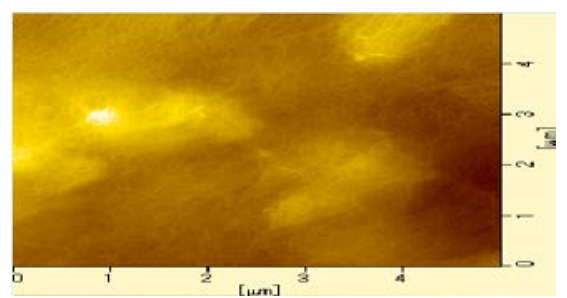

FIGURE IX. At $550^{\circ} \mathrm{C}$.

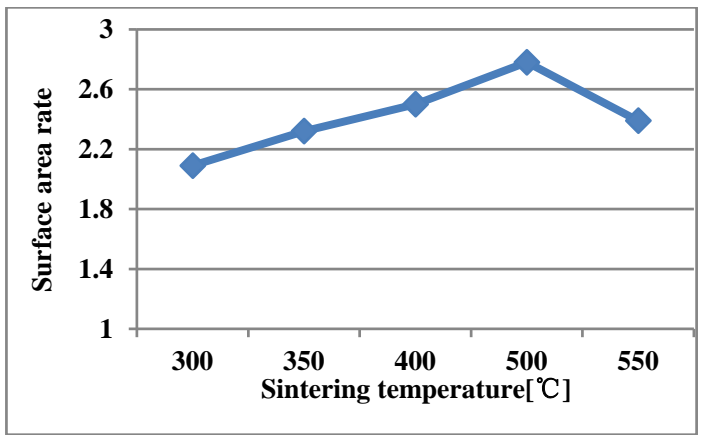

FIGURE X. SURFACE AREA RATE OF CNT ELECTRODE SINTERED AT DIFFERENT TEMPERATURE.

\section{CONCLUSION}

In summary, CNT is used as a counter electrode of a DSSC.The CNT counter electrode consisting of a large number of like bamboo structures exhibits low charge transfer resistance, large surface area, and fast reaction rates for reduction of $\mathrm{I}_{3}$ - ions. To coat CNT with FTO glass we use the EPD and controlled thickness of the CNT counter electrode. After EPD, we sintered it at different temperature and measured the surface area of the CNT electrode by AFM. Result of Measurement, surface area of CNT electrode changed when sintering temperature changed and CNT electrode sintered at $500^{\circ} \mathrm{C}$ had highest surface area of all CNT electrode sintered different temperature. Therefore sintering temperature is very important for CNT counter electrode and improvement in the conversion efficiency of DSSC used CNT electrode sintered at $500^{\circ} \mathrm{C}$ as a counter electrode is expectable.

\section{REFERENCES}

[1] Johann Cho, KatarzynaKonopka, Krzysztof Rozniatowski, Eva GarciaLecina, Milo S.P. Shaffer, Aldo R. Boccaccini. Characterisation of carbon nanotube films deposited by electrophoretic deposition, CARBON47, pp.58-67, 2009.

[2] S. Wu, H. Han, Q. tai, J. Zhang, B.L. Chen, S. Xu. Improvement in dyesensitized solar cells with a $\mathrm{ZnO}$-coated $\mathrm{TiO} 2$ electrode by rf magnetron sputtering, Applied physics letter, 92, pp. 122106, 2008. 
[3] C. S Chou, T Watanabe, Y. H. Huang, P. Wu. Optimization of ZnOcoated $\mathrm{TiO} 2$ working electrode and application in a dye-sensitized solar cell, Applied Mechanics and Materials, 481, pp P 117-120, 2013.

[4] J. Han, H. Kim, D.Y. Kim, S.M. Jo, S.Y. Jang, ACS. Water-Soluble Polyelectrolyte-Grafted Multiwalled Carbon Nanotube Thin Films for Efficient Counter Electrode of Dye-Sensitized Solar Cells, Nano4 pp.3503, 2010.

[5] S.H. Seo, S.Y. Kim, B.K. Koo, S. Cha, D.Y. Lee. Influence of Electrolyte Composition on the Photovoltaic Performance and Stability of Dye-Sensitized Solar Cells with Multiwalled Carbon Nanotube Catalysts,Langmuir26, pp. 10341, 2010.

[6] Guang Zhu, Likun Pan, Ting Lu, Xinjuan Liu, Tian Lv, Tao Xu, Zhuo Sun. Electrophoretic deposition of carbon nanotubes films as counter electrodes of dye-sensitized solar cells, ElectrochimicaActa, pp. 1028810291, 2011. 